\title{
Correction to: An effective dynamic immune optimization control for the wastewater treatment process
}

\author{
Fei $\mathrm{Li}^{1,2,3}$ - Zhong $\mathrm{Su}^{1} \cdot$ Gongming Wang ${ }^{3}$
}

Published online: 7 February 2022

C) Springer-Verlag GmbH Germany, part of Springer Nature 2022

\section{Correction to: Environmental Science and Pollution Research https://doi.org/10.1007/s11356-021-17505-3}

The correct third Author name is Gongming.

The Original article has been corrected.

Publisher's note Springer Nature remains neutral with regard to jurisdictional claims in published maps and institutional affiliations.

The original article can be found online at https://doi.org/10.1007/ s11356-021-17505-3.

Fei Li

lifei@bistu.edu.cn

Zhong Su

sz@bistu.edu.cn

Gongming Wang

wanggm@bjut.edu.cn

1 School of Automation, Beijing Information

Science \& Technology University, Beijing 100192,

People's Republic of China

2 Beijing Jingxinke High-End Information Industry

Technology Research Institute Co., Ltd, Beijing 100192,

People's Republic of China

3 Faculty of Information Technology, Beijing University of Technology, Beijing 100124, People's Republic of China 